\title{
International psychiatry - an agenda for the way forward
}

\author{
L. K. George Hsu
}

Professor of Psychiatry, Tufts-New England Medical Center, 750 Washington Street, Boston, MA 02111, USA, email ghsu@tufts-nemc.org

news release from the World Health O rganization (2003) suggested that a mere $10 \%$ of global health research is devoted to diseases that account for $90 \%$ of the global disease burden. While this comment refers primarily to research into infectio us and parasitic diseases, a similar trend may well be true for psychiatry, taken from a global perspective. A cursory glance at recent issues of World Psychiatry, the official journal of the World Psychiatric Association, will reveal articles describing recent advances in antidepressant treatment and other pharmacotherapies, psychotherapy and psychoanalysis, personality disorders, attentiondeficit hyperactivity disorder, and the genetics of mental illness. These topics are obviously important and the field cannot advance without such cuttingedge research. Most of the authors are, as expected, psychiatrists living and working in Western Europe or N orth America. This is also, of course, acceptable and important. The dissemination of scientific data is essential for advancing the field, and researchers who live and work in Europe and $\mathrm{N}$ orth America are generally the most qualified to do so. So, what's the problem?

The question is whether or how far this 'culturebound' perspective will advance the field of psychiatry for $90 \%$ of the non-Western world. Psychiatrists in rural $C$ hina or India or $C$ entral Africa reading a recent issue of World Psychiatry (to pursue that one example) will find the recent advances extremely stimulating (and that is very important for maintaining morale and motivation). However, it is extremely unlikely that they will be able actually to apply the knowledge in daily practice, except perhaps in a few cases that fit the context of these articles. Similarly, relatively few people in these geographical areas will benefit directly from the practice of psychiatry as described or presented in World Psychiatry.

I suggest that some of us should make an effort to channel our research towards four areas of what I suspect to be greatest need in the non-W estern world. I suggest these four areas simply to stimulate debate and discussion, and I may well be mistaken in my views. Also, I am not advocating a decrease in any of our current areas of research, basic or clinical - I am suggesting that perhaps some of us can begin to shift our focus and take a slightly different perspective.

\section{(1) Rehabilitation of the chronically mentally ill}

It seems unlikely that early intervention, or the widespread use of new atypical antipsychotic drugs and active community treatment, will be available any time soon in most parts of Asia and Africa. It is therefore a lamentable fact that many patients with psychotic disorders in these areas will become chronically ill. Efforts aimed at rehabilitation such as adaptation of the Fountain House approach (www.fountainhouse.org/) or that of the International Center for Clubhouse D evelopment (www.iccd.org) which de-emphasise (not challenge) the medical model may be more culturally acceptable to chronically mentally ill patients and their families.

\section{(2) Treatment of major depression by primary care physicians}

Major depressive disorder (MDD) has been identified as an important 'disease burden' (Murray \& Lopez, 1996). It seems unlikely that, in the non-W estern world, the need for treatment of MDD could ever be met by psychiatrists alone. The model of Katon et al $(1995,1996)$, which consists of training primary care physicians to treat MDD and using case workers to monitor antidepressant treatment and increase motivation for compliance, may be a more effective approach to lessen this disease burden. It is true that training of primary care physicians in the USA has not been particularly effective (Lin et al, 2001), but that alone should not deter further attempts to develop better training methods.

\section{(3) Developing a more culturally acceptable form of psychotherapy}

The psychologising of distress may be a recent Western phenomenon (Leff, 1988) but the need to share distress is probably universal. Therefore, perhaps there is a need for psychotherapy in any culture. While some efforts are being made to test whether some specific forms of psychotherapy may be effective in a different cultural setting (e.g. Verdell et al, 2003), clearly more should be done in this area. My own limited experience suggests that many people from the Asian subcontinent accept a problem-solving approach (D'Zurilla \& N ezu, 1999) better than they do a psychodynamic approach, but this should be studied.
Psychiatrists in rural China or India or Central Africa reading a recent issue of

World Psychiatry will find the recent advances extremely stimulating (and that is very

important for maintaining morale and motivation). However, it is extremely unlikely that they will be able actually to apply the knowledge in daily practice. 
Advances to

identify and treat mental disorders may not be possible unless the issue of the stigma of mental illness is tackled

\section{(4) Stigma of mental illness}

W hile data are lacking, those of us who have worked with different cultural groups will probably agree that the problem of stigma is greater in non-Western than in Western cultures. Advances to identify and treat mental disorders may not be possible unless the issue of the stigma of mental illness is tackled. There is almost no research into cultural differences in relation to stigma, or the reasons for such differences. Stangor \& Crandall (2000) have postulated that stigma may be related to a perceived threat which is amplified by social communication and sanctioned by so cietal mores. Is the stigma of mental illness greater in China than in the USA because it is perceived as a greater threat, or because social communication tends more often to exaggerate such threat, or because societal customs more often sanction such beliefs? I believe the need to study the stigma of mental illness is urgent.

\section{Conclusion}

I am not suggesting that, for instance, providing a 'Balint group' experience for a trainee from the 'Third World', or training in the genetics of mental illness, would lack benefit or utility. N evertheless, these are not the appropriate experiences needed to orientate the trainee to the 'greater' needs of the non-Western world. For all its intellectual challenges and fascinations, recent advances in psychiatry as reflected by research and practice in the Western world cannot be applied directly to meet the mental health needs of the non-Western world. Perhaps the Royal College of Psychiatrists can champion efforts directed at the four areas I have outlined.

\section{References}

D'Zurilla, T. J. \& N ezu, A. M. (1999) Problem Solving Therapy. $\mathrm{N}$ ew York: Springer.

Katon, W., Von Korff, M., Lin, E., et al (1995) Collaborative management to achieve treatment guidelines: impact on depression in primary care. Journal of the American Medical Association, 273, 1026-1031

Katon, W., Robinson, P., Von Korff, M., et al (1996) A multifaceted intervention to improve treatment of depression in primary care. Archives of General Psychiatry, 53, 924-932.

Leff, J. (1988) Psychiatry Around the Globe. London: Gaskell.

Lin, E. H., Simon, G. E., Katzelnick, D. J., et al (2001) Does physician education on depression management improve treatment in primary care? Journal of General Internal M edicine, 16, 614-619.

Murray, C. J. \& Lopez, A. D. (1996) Evidence-based health policy - lessons from the Global Burden of Disease Study. Science, 27, 740-743.

Stangor, C. \& Crandall, C. S. (2000) Threat and the social construction of stigma. In The Social Psychology of Stigma (eds T. F. Heatherton, R. E. Kleck, M. R. Hebl \& J. G. Hull), pp. 62-87. N ew York: Guilford Press.

Verdell, H., Clougherty, K., Bolton, P., et al (2003) Adapting group interpersonal psychotherapy for a developing country: experience in rural U ganda. World Psychiatry, 2, 114-120.

World Health O rganization (2003) N ew initiative to research and develop drugs for the world's most neglected diseases (25 June). See www.who.int/mediacentre/releases/2003/en/

\title{
How 'culture bound' is 'cultural psychiatry'?
}

\author{
Sushrut Jadhav
}

Senior Lecturer in Cross-cultural Psychiatry, Centre for Behavioural and Social Sciences as Applied to Medicine, University College London, 48 Riding House Street, London W1N 8AA, UK, email s.jadhav@ucl.ac.uk

\section{Stated}

provocatively, with a few exceptions, the discipline remains confined to the cultural boundaries of Euro-American countries, and predominantly serves the careers and social interests of their scholars. ultural psychiatry as a clinical specialty sprung mainly from Europe and North America, in order to respond to growing concerns of ethnic minorities in high-income countries. Academic psychiatrists pursuing comparative international studies on mental health, together with medical anthropologists conducting clinical ethnographies, contributed to its theoretical basis (Kleinman, 1987; Littlewood, 1990). What at first appeared to be a marginal specialty is no longer so. For example, the UK alone has witnessed a steady growth of the field, as evidenced by its mandatory inclusion in mental health training curricula, and the existence of several taught masters courses, academic positions in universities and three dedicated journals, as well as, more recently, lead papers in mainstream publications that have debated the cultural position of 'biology' itself (Timimi \& Taylor, 2004). Additionally, with a proliferation of clinical jobs for 'ethnic minority' services in hospital trusts across the country, there is ample scope for employment. The overall evidence indicates that 'cultural psychiatry' in the UK is now a specialty in its own right.

Stated provocatively, with a few exceptions (see Anthropology and Medicine, special issue, vol. 8, no. 1, April 2001), the discipline remains confined to the cultural boundaries of Euro-American countries, and predominantly serves the careers and social interests of their scholars. In most low-income countries, the specialty and its methods ironically retain the label 'cultural psychiatry' (rather than just plain standard local psychiatry). Moreover, scant teaching and research output from the latter countries is related to a more worrying scenario: psychiatry in low-income nations continues for the most part to rely on inappropriate texts, teaching and research designs imported from high-income countries. The large number of 'outsourced' mental health professionals from low-income countries working in the UK (and the ease with which they do so) is testimony to their psychiatric training, which in turn is predicated upon received wisdom from high-income countries. 